\title{
Estudo de caso: um olhar sistêmico para a psicoterapia individual
}

Estudio de caso: una mirada sistémica para la psicoterapia individual

Case study: a systemic view for individual psychotherapy

Juliana Rohde

Universidade de Santa Cruz do Sul - Rio Grande do Sul - Brasil

Dulce Grasel Zacharias

Universidade de Santa Cruz do Sul - Rio Grande do Sul - Brasil

\section{RESUMO}

O pensamento sistêmico entende que há interatividade entre os membros de um mesmo sistema, em retroalimentação ou feedback e, entendendo as famílias como sistemas, têm-se que os seus membros influenciam uns aos outros mutuamente. Por este motivo o presente estudo busca, através de um estudo de caso, demonstrar como este entendimento e a abordagem sistemica podem contribuir para a psicoterapia individual, através do caso da paciente A.M ${ }^{1}$. O entendimento se dará a partir do seu sistema familiar, uma vez que, apesar de os atendimentos terem ocorrido de forma individual, acredita-se que suas relações e interações familiares sejam muito significativas para compreensão da situação e condução da psicoterapia.

Palavras-chave: Abordagem sistêmica. Psicoterapia individual. Estudo de caso.

\section{RESUMEN}

El pensamiento sistémico entiende que hay interactividad entre los miembros de un mismo sistema, en retroalimentación $\mathrm{y}$, entendiendo a las familias como sistemas, se tienen que sus miembros influencian unos a otros mutuamente. Por este motivo el presente estudio busca, a través de un estudio de caso, demostrar cómo este entendimiento y el abordaje sistémica pueden contribuir a la psicoterapia individual, a través del caso de la paciente A.M. El entendimiento se dará a partir de su sistema familiar, una vez que, a pesar de que las atenciones han ocurrido de forma individual, se cree que sus relaciones e interacciones familiares son muy significativas para comprender la situación y la conducción de la psicoterapia.

Palabras-clave: Enfoque sistêmico. Psicoterapia individual. Estudio de caso.

\footnotetext{
${ }^{1}$ A paciente será identificada pelas iniciais para não expor sua identidade, tampouco comprometer o sigilo.
} 


\begin{abstract}
Systemic thinking understands that there is interactivity between members of the same system, through feedback and, understanding families as systems, have their members influence each other mutually. For this reason, the present study seeks, through a case study, to demonstrate how this understanding and the systemic approach can contribute to individual psychotherapy through the case of the A.M patient. The understanding of this case will be approached from their family system, since, although the attendances have occurred individually, it is believed that their relationships and family interactions are very significant for understanding the situation and conducting psychotherapy.
\end{abstract}

Keywords: Systemic approach. Individual psychotherapy. Case study.

\section{Introdução}

Atualmente, dentre as tantas possibilidades de se fazer ciência, a "visão sistêmica" é uma delas. Ela fornece o entendimento de que não é possível um determinado ramo científico manter-se independente dos demais, mas sim que todos estão de alguma forma interligados, complementando-se e influenciandosemutuamente. Com os grupos humanos, como a família, acontece da mesma forma. Seus membros constituem um sistema parcial que interage com outros sistemas parciais, constituindo uma totalidade que é mais complexa, permitindo uma visão global enriquecedora, que amplia nossos conhecimentos e formas de usá-los (Vasconcellos, 2008).

O pensamento sistêmico entende que há interatividade entre os elementos de um mesmo sistema, de forma circular, em feedback. Em uma família, os comportamentos de cada membro retroalimentam o comportamento dos outros membros, ou seja, há influência recíproca entre todos, não sendo possível identificar o que é "causa" e o que é "efeito" das atitudes, pensamentos e sentimentos de cada um (Osório, 2004).

Campos, Álvares e Abreu (2007) descrevem a família como um organismo dinâmico no qual ocorrem movimentos, dependendo das variáveis que estão incidindo sobre este organismo. Papp (1992) aponta que os membros da família não são vistos como possuidores de certas características inatas, e sim que estão manifestando um comportamento em relação ao comportamento de outros. Estes aspectos corroboram para justificar a escolha do enfoque deste estudo: um olhar sistêmico para o caso de uma paciente atendida em psicoterapia individual. O caso da paciente A.M será abordado a partir do seu sistema familiar, uma vez que, apesar de os atendimentos terem ocorrido de forma individual, entende-se suas relações e interações familiares comosignificativas para compreensão e condução da psicoterapia.

Ao longo do trabalho serão apresentados o histórico, o genetograma, o entendimento dinâmico, as hipóteses e demais aspectos pertinentes ao relato do caso. Depois se apresentará o referencial teórico, cujos pontos abordados serão diferenciação de self, triangulações e fronteiras, buscando conceituálos a partir da literatura e contextualizá-los ao relato que se apresenta. Por fim, as considerações finais.

\section{Método}

Trata-se de um estudo de caso, desenvolvido a partir dos atendimentos realizados com uma paciente em psicoterapia individual. Estes atendimentos aconteceram durante a realização dos estágios componentes curriculares do Curso de Psicologia de uma universidade do Rio Grande do Sul. Os atendimentos eram transcritos e relatados em supervisão, o que possibilitou a realização deste estudo. 
De acordo com Coimbra e Martins (2013), esta metodologia é utilizada preferencialmente quando a intenção é investigar uma realidade, compreendendo-a de forma integral, descritiva e interpretativa, em uma busca pela desocultação e pela descoberta. $\mathrm{O}$ estudo de caso permite que se investigue um contexto real e um conhecimento particularizado, construindo o conhecimento através da escrita científica, estruturada, interpretativa e crítica.

A paciente que empresta sua história para que este estudo se realize foi atendida em um serviço-escola. Por se tratar de menor de idade, os pais assinaram um termo de consentimento, autorizando que o processo terapêutico de sua filha fosse utilizado para fins de estudo e pesquisa, bem como publicação, desde que fosse mantido o sigilo quanto à identidade. A seguir se apresentará o relato do caso, incluindo histórico, genetograma, entendimento dinâmico, hipóteses e demais aspectos pertinentes; referencial teórico, cujos pontos abordados serão diferenciação de self, triangulações e fronteiras, buscando conceituá-los a partir da literatura e as considerações finais.

\section{Resultados}

\section{Relato do caso}

A.M. é uma menina de 11 anos, filha única do casal V. e A., juntos há 18 anos. Segundo informações dos pais, a gestação, apesar de ter acontecido dois anos antes do planejado, foi desejada e sem intercorrências, o parto da mesma forma. No entanto, o nascimento da filha gerou uma crise na relação conjugal, que naquele momento envolveu traição por parte do marido e uma separação de alguns meses, tendo os pais retomado o casamento quando a criança tinha oito meses de idade.

Os pais também relataram que desde muito pequena A.M. é uma criança ativa, optando sempre por brincar com crianças mais novas, comportamento que permanece inalterado. Atualmente o contato de A.M. com outras crianças para além dos colegas de escola restringe-se praticamente aos dois primos, que têm nove e dois anos.

Quem exerce os principais cuidados com a menina atualmente é sua mãe, uma vez que o pai viaja constantemente a trabalho (é caminhoneiro). Desde a metade do ano de 2015 a mãe de A.M. parou de trabalhar fora para ficar com a filha, que anteriormente ficava sob os cuidados da avó materna. De acordo com V. a avó era permissiva demais com a neta, de forma que os deveres de casa e estudos (está cursando o sexto ano de Ensino Fundamental) estavam sendo negligenciados e o rendimento escolar prejudicado. No início de 2016 V. começou a trabalhar no supermercado da família, onde A.M. fica com ela à tarde.

A paciente tem contato tanto com os avós maternos quanto com a avó paterna. Visita a avó paterna, que mora em outra cidade, em alguns finais de semana, e os avós maternos vê com mais frequência, pois na sexta-feira vai para a chácara em que moram retornando para casa somente no domingo. Há relações descritas como "boas" com a família extensa, como tios e primos, com os quais convivem e interagem com frequência.

Em relação à família de A., pai da paciente, sabe-se que seu pai é desconhecido. $\mathrm{Na}$ infância, ficou primeiramente aos cuidados dos avós, depois aos cuidados de tios e mais tarde passou a morar e ser assistido por sua mãe. A avó paterna, segundo informações da mãe de A.M, teve problemas com alcoolismo, assim como o pai da paciente, que há mais ou menos 15 anos teve uma internação hospitalar para tratar sua dependência. O pai de A.M., após essa internação, permaneceu por oito anos sem ingerir nenhuma bebida alcoólica, mas nos últimos sete anos tem voltado a beber em festas, datas comemorativas, pescarias e finais de semana, fazendo cada vez mais concessões ao uso de álcool. Esta situação preocupa muito sua esposa.

Quanto à família materna de A.M., V., diferente do marido que é filho único, possui duas irmãs, sendo uma delas adotiva. Esta 
irmã adotiva é uma prima, que passou a morar e ficar sob os cuidados dos pais de V. aos dois anos de idade. A outra irmã de V. é casada, possui uma relação bastante conflituosa com o marido, segundo informações da paciente A.M., e é mãe de L. e D., crianças com as quais A.M. tem bastante contato.

O casal (pais de A.M.) tem conflitos que são gerados pela discordância a respeito de como deve ser a criação da filha, ele acreditando que ela precisa ser mais independente e autônoma, e a mãe assumindo uma posição de reforçar os comportamentos infantilizados e egocêntricos da filha, não permitindo que ela exerça autonomia em relação a coisas simples do dia a dia, como, por exemplo, a gestão de seus materiais escolares. Um exemplo disso é que V. tem em casa um estoque de materiais (lápis, canetas, cola, borracha, etc.). Ela verifica todos os dias a mochila da filha, enquanto esta dorme, e substitui os materiais que estão no final (faz isso enquanto a filha dorme pois combinaram que ela arrumaria sozinha a mochila, há pouco tempo). V. não dá tempo para que a filha se dê conta da falta de algum material e solicite à mãe, pois se antecipa à demanda. Esse comportamento se repete em outras ocasiões.

Diante desta situação, o pai critica os comportamentos da esposa em relação à filha, diz que ela "mima demais" e que A.M. precisa ser "mais independente", "precisa crescer". No entanto, por passar muito tempo fora de casa, quando está não assume uma posição de estabelecer limites e incentivar a autonomia da filha, justificando que quando está perto "quer aproveitar".

A.M. foi diagnosticada com Transtorno Déficit de Atenção e Hiperatividade (TDAH) por volta dos oito anos, fazendo uso de medicação (Ritalina) desde então. A busca por atendimento médico naquela época foi motivada pelas dificuldades de aprendizado na escola e pela percepção dos pais de que ela "não parava quieta". Os pais referem ter percebido diferenças após início da medicação, principalmente na escola. A.M. também faz acompanhamento com fonoaudióloga, em função de ter uma dificuldade na pronúncia das palavras.

Essa pronúncia incorreta das palavras assemelha-se muito à forma como uma criança pequena se comunica. Também é importante referirque esta dificuldade tem reflexos sinificativos na vida escolar da menina, uma vez que ela escreve da mesma maneira que fala (exemplo: a palavra "laranja" é pronunciada por ela como "laranza", e a grafia da palavra corresponde à pronúncia).Em função disso, sofria com piadas e deboches dos colegas na antiga escola o que fez com que desenvolvesse uma vergonha de se expressar. Este ano trocou de escola, mudança que trouxe alterações positivas para o contexto de A.M., pois na nova instituição essa questão parece ser tratada com mais naturalidade por todos, inclusive pelos colegas, que não fazem deboches. 
Genetograma da família de A.M.

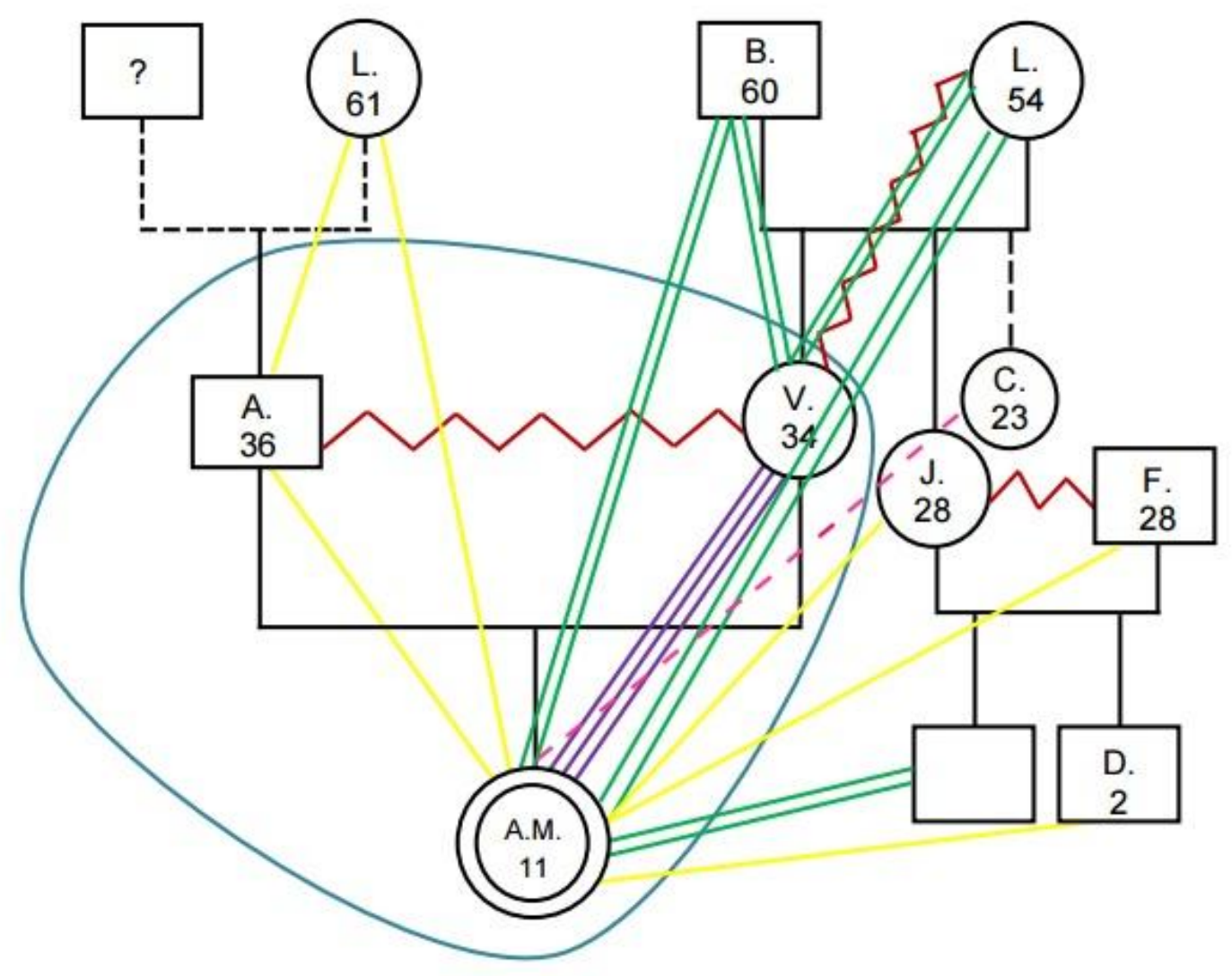

Legenda:

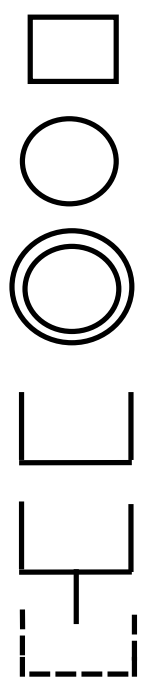

Homem

Mulher

Paciente identificado

Casamento

$\bar{\equiv}$ Relação forte e fusionada

—— Relação forte/íntima Relação normal

M Relação conflituosa

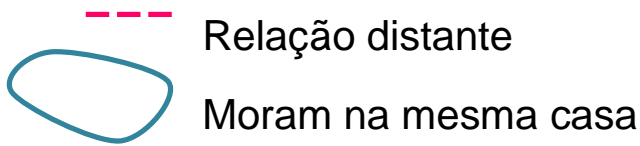

Filhos

Relação não oficial

Filhos adotivos

? Desconhecido 


\section{Motivo da procura por psicoterapia e impressões iniciais}

A.M. chegou ao serviço por indicação da fonoaudióloga com quem já fazia acompanhamento, tendo passado por acolhimento e sido encaminhada para psicoterapia individual. A queixa dos pais é de que a filha tem comportamentos muito infantilizados se comparada às outras crianças da sua idade, e que estava sofrendo bulliyng na escola em função da sua dificuldade com a fala. Os pais também apontam que A.M. não acata suas ordens sempre questionando e desobedecendo, bem como sempre busca ser o "centro das atenções". Também apontam que a filha é muito dependente, mas essa questão aparece principalmente como queixa do pai.

A paciente passou a ser atendida no serviço-escola em 2015 iniciando seu processo terapêutico com outra estagiária, que realizou 30 atendimentos ao longo do ano. No ano de 2016 ocorreram 31 atendimentos, com uma segunda estagiária.

A paciente A.M. nos primeiros contatos com a segunda terapeuta demonstrava-se inquieta e distraída, conversando com a estagiária de forma vaga e aparentemente desinteressada, enquanto explorava os brinquedos da sala. Os brinquedos que escolheu inicialmente e a forma como se comportava refletiam as informações prévias que havia sobre ela: muito infantilizada. Os brinquedos que escolheu eram extremamente simples, de fácil compreensão por crianças bem mais novas. No entanto, A.M. mostrou-se muito motivada e interessada por eles. Convidou a terapeuta para brincar, mas sempre dando ordens e rejeitando suas sugestões nas brincadeiras.

\section{Evolução do caso}

Desde o início da psicoterapia A.M. já apresentou evoluções significativas em relação à forma como lida com as provocações e piadas quanto à sua dificuldade de pronúncia das palavras. Ao passo que anteriormente magoava-se e evitava o assunto, hoje fala abertamente sobre o seu "falar errado", como a mesma refere. Hoje está claro que lida com a situação de forma mais madura, tendo em vista que antes ressentia-se quando era corrigida por alguém, o que não acontece mais.

Também é perceptível um amadurecimento da paciente, que passou a comunicar-se e expressar-se de forma mais elaborada, uma vez que antes sua comunicação verbal, vocabulário e forma de se expressar eram mais precários. A.M. também evoluiu no que se refere à forma de organizar suas brincadeiras e do papel que atribuía à terapeuta. Enquanto costumava brincar com vários brinquedos ao mesmo tempo, sempre dando ordens e deixando a terapeuta interferir muito pouco nas suas brincadeiras (tinha pouca flexibilidade, não tolerava que aquilo que ela havia decidido e estabelecido fosse feito de alguma forma diferente), passou aconseguir permitir interferências e mudanças.

Houve pequenas alterações no que se refere à autonomia de A.M., que agora começa a querer fazer algumas coisas sozinha, sem interferência dos pais. Essa demonstração de iniciativa em algumas situações é tolhida por eles e em outras há desistência por parte de A.M., que considera mais fácil, como ela mesma refere, deixar que façam por ela.

\section{Entendimento dinâmico e hipóteses dianósticas}

Mãe e filha estão fusionadas, emaranhadas, de forma que A.M., apesar de estar entrando na adolescência encontra-se muito pouco diferenciada em relação à mãe. Também há uma triangulação, uma vez que $\mathrm{V}$. tem medo que o marido volte a beber, supervisionando-o em relação a isso. Utilizase de A.M. para tentar mantê-lo afastado do álcool, mantendo-a afastada do pai quando este bebe. A filha, por sua vez, "não gosta que o pai beba", e aproxima-se da mãe quando este o faz, como uma forma de proteger-se.

Há conflitos entre o casal que são gerados pelo descompasso a respeito da forma 
que cada um acredita que deve ser a educação da filha, o que produz um reflexo na forma como cada um age em relação a ela (um mais permissivo, fazendo as coisas por ela e o outro mais rígido em alguns momentos, querendo que a filha haja com independência, mas não mantendo sua posição em muitas situações). A.M. percebe esta incongruência e desacordo dos pais, utilizando-se da situação. Quando um dos genitores nega ou não autoriza algo que ela pede, logo ela solicita ao outro, muitas vezes alcançando seu objetivo. Por não estarem afinados e seguros em relação ao estabelecimento de limites, tampouco na manutenção dos mesmos, A.M. muitas vezes não os reconhececomo figura de autoridade.

Quanto às hipóteses diagnósticas, podese pensar em uma relação fusionada com a mãe e papeis parentais pouco claros. Também se considera possível que haja dificuldade de diferenciação de self e fronteiras difusas (emaranhadas) entre o subsistema parental e A.M.

\section{Discussão}

Nichols e Schwartz (2007) esclarecem que se cada um dos membros de uma família é modificado, continua provocando mudanças nos demais de forma sincrônica. Os mesmos autores ainda afirmam que qualquer dificuldade pode ser tratada com terapia individual ou de família, mas que algumas situações são mais propensas a intervenções familiares, tais como problemas com filhos, queixas sobre o casamento ou outros relacionamentos íntimos, hostilidades familiares e sintomas que se desenvolvem no indivíduo concomitantemente a uma importante transição familiar.

No entanto, nem sempre há possibilidade de terapia familiar nessas situações, como no caso da paciente A.M. O entendimento a partir do viés sistêmico, porém, não fica impossibilitado, tanto que será abordado a seguir, buscando aprofundar alguns aspectos que se evidenciam no sistema familiar de A.M. Estes aspectos teóricoscontribuiram imensamente para compreensão do caso e para o andamento da sua psicoterapia individual.

\section{Diferenciação de self}

Toda criança nasce fusionada, indiferenciada em relação à sua família. Sua principal tarefa ao se desenvolver será diferenciar-se, para alcançar sua autonomia e independência. Em sua família, as crianças vivenciam duas situações: pertencimento e diferenciação. O pertencimento está ligado à participação, ao saber-se membro da família, à partilha das crenças, valores, regras, mitos e segredos. Diferenciação refere-se à afirmação de sua singularidade, sua individuação e ao seu direito de pensamento e expressão independente dos valores da sua família (Martins; Rabinovich; Silva, 2008).

Lima (2014) refere que a diferenciação de cada pessoa se inicia justamente no processo desenvolvimentalda família, à medida que as relações se ajustam para lidar com entradas, saídas e desenvolvimento dos membros, e que estes processos exigem transformações significativas ao longo do ciclo vital. A autora aponta ainda que a diferenciação do self das pessoas permeia as fases do ciclo da família (fase de aquisição, fase adolescente, fase madura e fase última, propostas por Cerveny e Berthoud (1997/2012, apud Lima, 2014, p. 10), variando de pessoa para pessoa e de família para família, bem como a diferenciação do self é fundamental na avaliação do funcionamento individual e familiar.

Bowen (1979) citado por Santos (2008, p. 12) explica a diferenciação do self como um conceito intrapsíquico e inter-relacional, esclarecendo que a diferenciação intrapsíquica se refere a uma capacidade de distinguir pensamentos de sentimentos, e a diferenciação inter-relacional consiste na capacidade de um indivíduo de dinstinguir sua identidade das outras pessoas. Bowen classifica a diferenciação dos indivíduos a partirde uma escala, que tem em um extremo indiferenciação e fusão de ego, com pouca clareza do "si mesmo" (relação simbiótica), e 
no outro extremo tem autonomia de forma significativa.

Ao retomarmos o que já foi exposto, a respeito de que toda criança nasce fusionada à sua família, e que terá como tarefa no seu desenvolvimento diferenciar-se para adquirir autonomia e independência (Martins; Rabinovich; Silva, 2008), Lima (2014) aponta que os pais devem favorecer este processo apresentando fronteiras flexíveis. Desta forma permitemque o filho se sinta seguro para alçar vôo e enfrentar novas fases, dando-lhe apoio, incentivo e orientação. Se o filho desenvolve um self menos diferenciado, pode desenvolver também baixa tolerância às frustrações e ceder facilmente à influência de outras pessoas, tornando-se dependente delas. Poderá ainda possuir menos capacidade intelectual para agir e, se sua diferenciação for mínima, possivelmente terá dificuldades relacionais.

No caso da paciente A.M. percebe-se uma dificuldade de diferenciação em relação aos pais. Não é esperado que aos 11 anos ela alcance um alto nível de diferenciação, pois ainda está crescendo e se desenvolvendo enquanto sujeito, mas sim algum grau deste processo. A.M. não demonstra inciativa para resolver questões comuns do seu dia a dia, tampouco é incentivada pelos pais a fazê-lo. Aocontrário, a mãe, que é sua principal cuidadora, costuma antecipar-se às ações da filha, resolvendo tudo e deixando as coisas prontas antes que A.M. se dê conta da necessidade daquilo. Na relação das duas, uma adentra com tanta facilidade o espaço da outra que muitas vezes não está claro onde "termina" uma pessoa e onde "começa" a outra. Essa relação também nos leva a pensar sobre os triângulos $\mathrm{e}$ as fronteiras nesta família.

\section{Fronteiras}

Ao discorrer sobre fronteiras, Minuchin (1990), explica primeiramente o que é família: um sistema, composto por subsistemas que permitem o exercício das suas funções. Díades como mãe-filho e esposo-esposa podem ser subsistemas esperados, entretanto existem inifitas possibilidades, conforme a configuração e estrutura da família. As fronteiras têm como função proteger a diferenciação dossubsistemas, e são regras que definem quem participa do que, e como. "Por exemplo, a fronteira de um subsistema parental é definida quando uma mãe diz ao seu filho mais velho: "você não é o pai do seu irmão. Se ele está andando de bicicleta na rua, diga-me e eu o farei parar"” (p. 58). Importante também destacarque cada subsistema tem funções específicas e faz exigências aos seus membros.

A funcionalidade de uma família pressupõe fronteiras de subsistemas que sejam nítidas e suficientemente definidas, a fim de permitirque os membros exerçam seus papeis e funções sem interferências indevidas, e possibilitarque aconteça contato entre os membros de um subsistema e outro. A composição dos subsistemas não é tão importante quanto a nitidez das suas fronteiras, uma vez que um sistema parental, por exemplo, pode funcionar bem com uma avó ou criança parentalizadas, desde que as linhas de responsabildade e autoridade sejam claras (Wagner et. al., 2011).

Quando há excesso de limites entre as fronteiras elas podem tornar-se rígidas, levando a um padrão de funcionamento desligado, em quea comunicação é difícil. O oposto também acontece, quando as fronteiras não estão nítidas e não há limites entre os subsistemas. Estas fronteiras tornam-se então difusas, de maneira que se produz um funcionamento emaranhado. Um exemplo é a tendência de haver um emaranhamento entre mãe e filhos quando estes são pequenos, eo pai acaba ficando em uma posição de desligamento. Esses dois extremos são áreas para possível patologia, de forma que o terapeuta, em muitas situações, terá que direcionar seu trabalho no sentido de tornar nítidas as fronteiras difusas e abrir espaço nas fronteiras rígidas (Minuchin, 1990).

Minuchin (1990) também explica que membros de subsistemas ou famílias emaranhadas podem prejudicar-se no sentido 
de renunciarem à sua autonomia, uma vez que esta renúncia é necessária para que exista o sentimento de máximo pertencimento. Em sistemas emaranhados, os papeis individuais não se separam dos familiares/conjugais, e as pessoas quase são "parte uma da outra". Acrescenta que a falta de diferenciação de um subsistema desencoraja essa autonomia e o domínio dos problemas, de forma que este emaranhamento faz com que o comportamento de um membro repercuta de forma imediata nos outros, pois "a família emaranhada responde a qualquer variação do habitual, com excessiva rapidez e intensidade" (p. 60-61). A análise dos subsistemas familiares e das fronteiras proporciona ao terapeuta um quadro da família, um diagnóstico que poderá auxiliálo a orientar suas ações e nortear a terapia.

$\mathrm{Na}$ família de A.M. percebe-se claramente essa difusão das fronteiras, de forma que a autonomia dos membros está muito prejudicada, especialmente de A.M. e de sua mãe, V. Uma está tão emarahada à outra que A.M. não consegue desenvolver sua autonomia, pois teria que renunciar, mesmo que minimamente, ao sentimento de pertença. Ao mesmo tempo, com V. acontece a mesma coisa, pois não consegue fazer essa renúncia em relação à filha, deixando de ter seu espaço, sua individualidade, sua autonomia, não permitindo que a filha desenvolva a sua também. V., ao falar da filha, reconhece que tem uma dificuldade de "tirar ela do centro da vida", e refere que precisa prestar atenção para que não deixe sua relação com A.M. tomar conta de todos os seus espaços e momentos. Já o pai está numa posição de desligamento em relação ao subsistema mãe-filha, estabelecendo-se entre esse subsistema e A. uma fronteira rígida.

Em relação ao subsistema parental, deve delinear-se entre ele e os filhos uma fronteira que permita acesso a ambos os pais, mas que os exclua das funções conjugais. As principais funções do subsistema parental são nutrir, controlar e orientar, sendo necessário também o uso da autoridade (Minuchin, 1990). Santos (2008) aponta que os pais não exercendo suas funções com o consenso e autoridade necessários, consequentemente, o filho terá maiores dificuldades de desenvolver sua relação com o poder e o controle de suas emoções. O subsistema parental da família de A.M. tem dificuldades de exercer sua autoridade, buscando um controle excessivo e restritivo, o que é contestado por ela. Minuchin (1990) refereque esta situação ocorre quando o subsistema parental é fraco e o controle não se dá a partirda autoridade e de papeis claros. O papel do terapeuta nesta situação é de auxiliar os subsistemas a negociarem e se acomodarem entre si.

\section{Triângulos}

Martins, Rabinovich e Silva (2008) explicam que triângulos podem aparecer nas interações emocionais estabelecidas no sistema familiar. Apontam que a triangulação refere-se a um sistema inter-relacional entre três pessoas, estando envolvidos sempre uma díade e um terceiro elemento, que será chamado para participar quando o nível de desconforto e de ansiedade aumentar entre as duas pessoas.

Guerin, Fogarty, Fay e Kautto (1996 apud Santos, 2008, p. 14) relatam que num triângulo com filho sintomático existe uma ligação estreita entre um dos cônjuges e o filho, ao passo que o outro cônjuge fica numa posição de distância e solidão. $\mathrm{O}$ filho aprisionado por esta relação começa a expressar, por meio da conduta sintomática, seus sentimentos, sendo o sintoma uma tentativa de encobri-los.

Em situações de menor tensão, os triângulos permanecem latentes, ressurgindo quando os conflitos emergem novamente. Portanto são influenciados pela ansiedade, tornando-se mais ou menos ativos conforme as situações tensoras. Em um sistema familiar pode-se observar triângulos que se formam e se desfazem de forma repetitiva, de forma que épossível entender que não são fixos nem estáticos, mas que se deslocam conforme o nível de ansiedade e dinâmica interna da família (Martins; Rabinovich; Silva, 2008). 
O motivo que aciona este mecanismo de comportamento está ligado ao fato da díade experimentar desejos como necessidades que o outro não satisfaz. Nesta situação existem duas possibilidades de movimentos: ou o indivíduo se afasta e procura uma terceira pessoa para aliviar sua tensão ou aproxima-se e aceita o controle do outro através de suas exigências. [...] $\mathrm{O}$ indivíduo chega a este ponto pelo desejo de evitar problemas com seus pares, assim como o rompimento do vínculo. Como a mudança não é possível, um terceiro elemento pode ser incorporado ao grupo. Embora a díade tenha a intenção de estabilizar a relação, com frequiência termina por criar mais dificuldades, pois a triangulação não permite a diferenciação de seus membros (Bowen, 1979 apud Santos, 2008, p. $15)$.

É possível observar uma triangulação na família da paciente sobre a qual discorre este estudo. A díade V. e A. triangula-se com A.M., uma vez que $V$. tem medo que o marido volte a ingerir bebidas alcoólicas de forma abusiva, supervisionando-o em relação a isso. Quando o marido faz uso de bebida alcoólica, o nível de ansiedade na relação do casal elevase, e V. necessita convocar A.M. para a relação, buscando resoluções (da situação e da sua ansiedade). A mãe de A.M. utiliza-se da filha para tentar manter A. afastado do álcool, mandando-a para longe do pai quando este bebe (costumeiramente manda a filha para a casa dos avós, ou as duas saem para passear). A filha, por sua vez, "não gosta que o pai beba", e aproxima-se da mãe quando este o faz.

\section{Considerações finais}

Terapia é uma experiência construída de encontro humano, um tipo especial de arte com um conjunto de objetivos e formas de atingi-los. [...] Terapia não diz respeito a verdades, mas a escolhas. Cada terapeuta terá que fazer escolhas quanto à direção a tomar, à linguagem a adotar, às metáforas selecionadas, aos sentidos oferecidos e às mudanças desejadas. E nenhuma formação terapêutica está completa até que o terapeuta aprenda a verdade da incerteza (Minuchin; Nichols; Lee, 2009, p. 231-232).

Esse trecho do livro Famílias e casais: do sintoma ao sistema de Minuchin, Nichols e Lee reflete um pouco daquilo que foi sentido ao deparar-se com a paciente A.M. As escolhas e direções a seguir eram um leque de possibilidades, podendo ser enfocada a questão do TDAH, a questão da dificuldade de fala e a questão das dificuldades na escola como um transtorno de aprendizagem, possibilidades todas que foram consideradas. No entanto, ao olhar para sua família, e ao pensar a partir do enfoque sistêmico, optou-se por seguir este caminho, tentando entendê-la a partir das relações que a produziram e das relações que estabelece com seu sistema familiar.

Este caso, neste momento, é pensado a partir das perspectivas apresentadas no decorrer deste estudo, com as relações de A.M. visualizadas e entendidas a partir da diferenciação de self, das fronteiras entre os subsistemas familiares e das triangulações. No entanto, nada impede que novas informações e acontecimentos alterem este olhar e modifiquem o entendimento.

Ser terapeuta de A.M. contribuiu para que se entendesse, de forma mais prática, um pouco a respeito da "verdade da incerteza", de que nada é fixo, mas sim dinâmico e mutável, assim como os triângulos, que às vezes estão latentes e inativos, mas que, de repente emergem para tentar dar conta de uma situação. No momento, em relação à A.M., as questões abordadas são aquelas que se evidenciam para o olhar da terapeuta, são o caminho escolhido, apesar de, como qualquer outro, ser incerto. 


\section{Referências}

Campos, E. M. P.; Álvares, M.; Abreu, P. Infância e família. In: Mello Filho, J.; Burd, M (Orgs.) (2010). Doença e família (pp. 205-216). São Paulo: Casa do Psicólogo.

Coimbra, M. N. C. T.; Martins, A. M. O. (2013). O estudo de caso como Abordagem metodológica no ensino superior. Nuances. São Paulo, 24(3), 31-46. Recuperado de http://revista.fct.unesp.br/index.php/Nuance s/article/viewFile/2696/2360

Lima, M. C. S. (2014). Filho: uma experiência de estranhamento. 34 p. Trabalho de conclusão de curso (curso de Psicologia) Centro Universitário Jorge Amado, Salvador. Recuperado de http://www.cefacbahia.org.br/pag_internas/ publicacoes/pdf/historico/tcc_MCS091214. pdf

Martins, E. M. A.; Rabinovich, E. P.; Silva, C. N. (2008). Família e o processo de diferenciação na perspectiva de Murray Bowen: um estudo de caso. Psicol. USP. São Paulo, 19(2), 181-197. Recuperado de Http://Pepsic.Bvsalud.Org/Pdf/Psicousp/V1 9n2/V19n2a05.Pdf

Minuchin, S. (1990). Famílias: funcionamento e tratamento. Trad. Jurema Alcides Cunha. Porto Alegre: Artes Médicas.

Minuchin, S.; Nichols, M. P.; Lee, W. (2009) Famílias e casais: do sintoma ao sistema. Porto Alegre: Artmed.

Nichols, M. P.; Schwartz, R. C. (2007). Terapia familiar: conceitos e métodos. Trad. Adriana Veríssimo Veronese. Porto Alegre: Artmed.

Osório, L. C. A família como sistema. In: Mello Filho, Júlio de; BURD, Miriam (Orgs.) (2004). Doença e família. São Paulo: Casa do Psicólogo, p. 29-42.

Papp, P. (1992). O processo de mudança: uma abordagem prática à terapia sistêmica da família. Trad. Maria Efigênia S.R. Maia e Claudine Kinsch. Porto Alegre: Artes Médicas.

Santos, N. E. B. (2008). A triangulação e seus múltiplos aspectos no contex to familiar: um olhar relacional-sistêmico. 33 p. Trabalho de conclusão de curso (especialização em terapia relacional sistêmica) - Familiare Instituto Sistêmico, Florianópolis.

Recuperado de http://www.institutofamiliare.com.br/downl oad_anexo/nara-elisete-bender-dossantos.pdf.

Vasconcellos, M. J. E. (2008) (7). Pensamento sistêmico: o novo paradigma da ciência. Campinas: Papirus.

Wagner, A. et al. (2011). Desafios psicossociais da família contemporânea: pesquisas e reflexões. Porto Alegre: Artmed.

Dados sobre as autoras:

- Juliana Rohde é acadêmica do curso de Psicologia da Universidade de Santa Cruz do Sul. Integrante do grupo de pesquisa "Realidade, Exclusão e Cidadania na Terceira Idade". Realizando estágio curricular junto ao CAPS I no município de Candelária-RS.

- Dulce Grasel Zacharias possui graduação em Psicologia pela Universidade do Vale do Rio dos Sinos (1985) e mestrado em Desenvolvimento Regional pela Universidade de Santa Cruz do Sul (1999). É especialista em Psicodiagnóstico Clínico pela PUC/RS. Tem formação em Psicologia clínica na área sistêmica pelo DOMUS, atendendo na modalidade individual, casal e família. Desenvolve suas atividades profissionais na Universidade de Santa Cruz do Sul, tem experiência na área de Psicologia Clínica, com ênfase em Desenvolvimento Social, da Personalidade, tratamento e prevenção. Atuando principalmente nos seguintes temas: família, casal, conflitos, escolha profissional, adolescentes e drogadição. É docente na Instituição e supervisora de estágio em sistêmica foi chefe do Departamento de Psicologia de 2008 a dezembro de 2013. Coordenadora do Curso de Psicologia por 2 anos(20014-2015). Atualmente chefe do departamento de Psicologia. Desenvolve também atividades de psicoterapia em clínica privada. 